\title{
Exploring the Chemistry of Datafication Control - Pathways for a Trust-Enabling Use of Smart Workplace Technology
}

\author{
Simon D. Schafheitle \\ University of St.Gallen \\ simondaniel.schafheitle@unisg.ch
}

\author{
Antoinette Weibel \\ University of St.Gallen \\ antoinette.weibel@unisg.ch
}

\author{
Alice Rickert \\ University of St.Gallen \\ alice.rickert@unisg.ch
}

\begin{abstract}
Organizations experiment with how smart technology can be used to manage employees since before COVID-19 and the possibilities seem almost limitless. However, the question of how this can be achieved without impairing the so-needed trust inside organizations is yet to answer. Hence, in this study, we employ a crisp-set QCA to investigate what trustenabling datafication control configurations look like. Drawing on unique survey data from Switzerland, we show that datafication control can go hand in hand with trust if organizations make efforts for employeecentricity. Further, we can reveal four distinct ways of how organizations can implement employee-centricity to mitigate possible trust-impairing signals that stem from augmented data-gathering and analysis capabilities. Our results contribute to the still heated debate on the duality of control and trust. They also help leaders to navigate through the unmanageable multitude of possible and even trust-toxic combinations.
\end{abstract}

\section{Introduction}

A recent Mc Kinsey Global Executive study has shown that the COVID-19 crisis has strongly accelerated the digitization of companies' internal processes by a rough estimate of four years [1]. We assume that concurrently the so-called "datafication" of employees, i.e. the process of translating their idiosyncrasy and social relations at work into quantifiable data has been equally on the rise [2]. This has become evident in newspaper reports about organizations deliberately experimenting with time tracking software or team-based workforce analytics to control employees [3, 4]. Such software and the accompanying smart technology are used to monitor employee performance and communication patterns, to derive new insights on individual performance, or to analyze, for instance, how teamwork can be better structured. Possibly these insights are also used for prescriptive analytics making the "automation of leadership" possible, where datafication nudges or tells employees how to behave more efficiently and appropriately, without human involvement [5]. Meanwhile, COVID-19 has heavily strained interpersonal relations in organizations, and the advent of datafication is feared to diminish the quality of relationships in companies even further $[6,7]$. Hence the ability to sustain or even build trust inside the organization, and therewith between employees, leaders and their employer is paramount $[8,9]$ and likely a prerequisite for effective datafication control enactment.

Yet how trust and datafication control relate, and especially how such technologically augmented ways to monitor, support, and direct employees are related to trust inside the organization is still a matter of a heated debate $[10,11]$. Therefore, in this study, we investigate how datafication, as means to enact organizational control, relates to trust inside the organization. We understand datafication control as a smart technologysupported process, by which the attention of employees and their motivation to act is directed towards the achievement of the organization's objectives [12]. More specifically, we explore controls that are supported by smart technology and thereby enable "an entity to function appropriately and with foresight in its environment" [13]. Employees thus face datafication control where they become more and more visible and subject to automated (HR) decision-making. Schafheitle and colleagues [14] have shown how datafication expands traditional organizational control considerably as their morphological analysis has revealed more than 230 '000 possible datafication control configurations. This adds to the complexity for organizations on how to orchestrate an effective deployment of datafication control configurations and enables a variety of routes how they can impact trust positively or negatively.

However, most research on the interplay of datafication control and trust has been directed towards the question of how datafication relates to trust in technology [i.e., see 15]. Yet relatively little is known on how trust inside the organization is impacted through the use of smart technology; let alone through 
datafication controls. For example, research on electronic performance monitoring [16] primarily examines its impact on employee strain, privacy, or justice perceptions and, if anything, its impact on trust in direct supervisors [17]. In this paper, however, we define trust inside the organization as a proxy for "trust as the enacted principle" across all organizational relationships", hence with no fixed trustor-trusteedirection. Rather, we are interested in how strong trusting beliefs are shared across different roles or levels, how one's willingness to be vulnerable determines his/her way of interpreting and approaching his/her counterparts, hence the extent to which organizational relationships are characterized by trust [18]. We focus on trust inside the organization, as this type of trust is strongly linked to enabling employees to cope with situations characterized by change or perceived lack of control. It helps them in dealing with any kind of possibly anxiety-creating environments, for instance, those crafted through invasive technologies [9]. Empirically, we rely on survey data about the use of smart technology from a senior HR-management perspective, considering them as key informants on "what is going on" inside the organization with regards to smart technology deployment and trust from a bird's eye view [19]. To explore datafication control configurations and their impact on trust inside the organizations, we reanalyze this Likert-scale survey data by calibrating it into crisp-set format, suitable to be analyzed via qualitative comparative analysis [csQCA, see 20]. Our results show various ways how datafication control can be enacted in a trust-enabling way. Across all datafication control configurations, the role of the organization is pivotal as it needs to take an active stance in designing datafication control in an employeecentric way. Our results indicate that neither datafication-augmented data-gathering possibilities nor its prescriptive automation potential per se impair trust as long as employees' view is integrated.

\section{Datafication control systems and trust}

\subsection{Configurational view of datafication control}

We define organizational control as any process by which the organization, managers, or organizational members, direct the attention, motivate, and encourage employees to act in desired ways to achieve the organization's objectives [21-23]. Controls can be either codified and formal or social and informal [23] and may be directed towards inputs, processes/behaviors, and outputs/performance. When combined with smart, hence foresighted, technology for data-gathering and interpretation, a new information phenomenon emerges that creates finer levels of granularity and scalability of information [24]. This has been termed datafication and characterizes the process of transforming artifacts of personality and social life into computerized data to generate new forms of value [2].

Building on insights from Schafheitle and colleagues [14], we argue that such technologies have altered "analog" organizational control. Hence, we now refer to it as "datafication control". Smart technology has already taken up on critical control functions (i.e., such as performance monitoring or rewarding, see [25]) and expands its scope to spheres that were not targeted in the "analog world". For instance, datafication control expands traditional organizational control, by codifying norms and sentiments. Additionally, it also alters traditional organization control by enabling the automatic generation of the control targets - namely employee or even organizational objectives. In practice, organizational control processes have been increasingly augmented by such smart technologies [26]. One prominent example is Amazon, where algorithms accelerate working rates to "optimize" employee performance [27]. Companies like WorkSmart even pride themselves on measuring and enhancing employee's productivity by taking screen- and webcam shots, tracking mouse clicks, and keystrokes [28].

In addition, datafication control should be understood as a control configuration. In this view, control elements, for instance, monitoring direction (behaviors or outcomes) or evaluation technology (descriptive or prescriptive) are not explored separately but as elements of an interdependent system. More specifically, we explore such a system with the lens of what Cardinal and colleagues [12, p. 570] have termed a "strong holistic approach". This approach emphasizes the combinatory and complementary logic of various control elements within one system, i.e. how control elements interact and blend to be or become effective. Capturing datafication control as a control configuration lends three important vantage points. First, it is well suited to account for the complexity of datafication control which enables a myriad of new options that have not been captured in "analog" organizational control. Second, thinking in control configurations allows researchers to analyze combinations and complementarities in non-linear, asymmetric, and equifinal ways [23, 29]. Non-linear means that the influence of one control element can be dependent on the common interaction with other elements regarding a specific outcome criterion. The assumption of asymmetry implies that also the absence of a control element can be fundamental for an outcome to occur. Equifinality, signifies several unique control configurations impact an outcome in the same fashion. Thirdly, this interplay can then be studied with any effectiveness criteria in mind [30, 31], such as trust, 
which remains unexplored in to-date organizational behavior and HR management research [10, 32].

\subsection{Datafication control systems and trust}

We suggest that exploring datafication control configurations related to the outcome of trust inside the organization is of particular interest. Scholars from a variety of disciplines agree that the impact on trust inside the organization seems critical for a successful deployment of datafication control [33]. Owing to both the new complexity of datafication controls and also because datafication technology functions as an opaque "black-box", employees' trust seems to be inevitably affected particularly regarding its core building blocks [10]: (1) vulnerability and (2) positive expectations.

First, datafication control makes employee vulnerabilities towards various organizational members more salient; hence trust is needed to "bridge" them. Concerning employees' trust in their employer, augmented data-gathering capabilities of datafication controls make panoptic states for employees more likely, where close, constant, and all-encompassing datafication highlights employees' vulnerability towards the employing organization which decides on pay, promotion, and staying options [8]. With regards to trust in leaders, datafication control's augmented dataanalysis capabilities, that bear automation potential, make it more difficult for employees to appeal to a leader's empathy [34]. Therefore employees might feel their opportunities for growth and development to be at the mercy of a non-living and non-context-sensitive entity [35]. Additionally, employees' vulnerability towards peers seems to be affected. Hereby, employees might feel more vulnerable because of dataficationheightened transparency, which can easily turn into contrastive comparison, a form of competition involving envy and suffering [36].

Secondly, datafication controls make it more difficult for employees to form positive expectations on their various trust counterparts' future intent or behavior. Regarding their trust relationship with the employer, the increased internal complexity and combinatorics of datafication controls make unanticipated and undesirable side effects probable. These include the often-cited transparency paradox [37], low-trust signals, or fraud labeling and manifest, for instance, if employee consent is required, yet information of datafication controls' functioning is incomprehensible [38], cannot be explained [39], or is obtained by a generic clause in the employment contract. Employees' trust in leaders might be negatively affected by datafication controls "blackbox"-character, because "two-leader"-situations emerge [35]. The black-box character of datafication controls likely threatens the sovereignty of observation from leaders and, hence, employees might face (HR) decisions, where leaders lack information of what employee data has been gathered and why it has been analyzed [25, 40]. "Two-leader"-situations become particularly trust-problematic because they lead to employees finding themselves in situations, where human leaders' role-prescribed responsibilities blur (e.g., who takes (moral) responsibility for decisions?) or conflicting decisions of human leaders and algorithms appear [e.g., trust in datafication controls becomes a "poisoned chalice", see 41]. With regards to trust in peers, the double-edged nature of technologyaugmented transparency might put positive expectations to the test. For instance, employees notice that their peers are only concerned with "flaunting performance" to gamble with the datafication controls, free-ride, or that "everything I know about you, I can use against you"-norms emerge. Because of this rather fuzzy mélange of effects on employees' trust in various trust referents and their likely interactions across levels, a focus on trust beliefs inside the organization as enacted principles seems particularly warranted.

\section{Research design and methods}

Our paper aims to explore the causal complexities pertinent to the trust-enabling use of datafication controls inside workplaces. To this end, we conduct a crisp-set qualitative comparative analysis (csQCA) that allows us to explore how datafication control elements (labeled as causal conditions) combine effectively so that trust inside the organization is not impaired [42]. In other words, our analysis reveals what datafication control elements are necessary and/or what combinations are (jointly) sufficient for trust to remain as an enacted principle [43].

Although rather novel in OB research [44], csQCA qualifies for answering our research question because it analytically treats cases (here companies) as manifestations of configurations of causal conditions. Hence, our analytical goal here is to unfold what configurations turn out as internally consistent across cases to make our outcome of interest, i.e., trust emerge $[45,46]$. To this end, csQCA establishes cause-effect relationships via set-theoretic sub- and superset relations: Here, this means to analyze the logical relationships of causal conditions inherent in the cases with regards to trust (in practical parlance: is the datafication control element A necessary for trust, i.e., does it not occur without A? Or, is B sufficient for trust, i.e., does it occur without B but, whenever B is present, trust also occurs?). Causal complexity is disentangled via Boolean AND/OR/NOT truth table analysis, analyzing all logically and theoretically possible 
combinations of the datafication control elements [29]. Hence, and different from net-effects-oriented analyses, QCA methodologically mirrors the basic assumptions of the configurational theory - that a datafication control system is made up of various elements that can combine in a non-linear, asymmetrical, and equifinal way [14, 29]. Additionally, the method is powerful in analyzing complex, multi-level organizational phenomena because, in Charles Ragin's [47] words, it seizes the benefits from both, the quantitative and the qualitative world. Practically, it relies on data, where our case companies have calibrated membership scores (i.e., similar to numerical variable expressions) in sets of causal conditions (i.e., similar to independent and dependent variables). Different from Likert-scale measurement, the process of calibration makes such membership scores meaningful themselves because it urges researchers to incorporate external standards, that stem from case- and context-knowledge as reference points. For instance, 100 degrees Celsius, as a calibrated measure, is directly interpretable because it refers to the side point of water as an external standard. Relatedly, the method's case- and context-sensitivity also materializes in that a meaningful interpretation of the resulting causal recipes requires researchers to assess causal complexity across cases (here: what do trustenabling datafication control configurations look like and why are they distinct from each other?) and withincases [i.e., what distinguishes the empirical cases, that make up one particular configuration?, see 47, 48]. Hence, with this method, each case company's idiosyncrasy, in terms of how datafication control is implemented and enacted is disentangled as configurational patterns and such patterns are generalized across relevant cases [47, 49].

In this paper, we adopt an explorative-oriented crisp-set version of QCA where cases can have either 1 (fully in) or 0 (fully out) as set membership score in each causal condition and the outcome. We chose this version because cumulative knowledge on how datafication control configurations can be enacted in a trust-enabling way is scarce. Hence we cannot develop strong assumptions based on the current state of knowledge $[10,12]$. The "discovery" nature of csQCA allows us to still fully seize the benefits of QCA as a means of disentangling causal complexity. The rather "coarsegrained" calibration enables us to contribute rich case and context knowledge, via comparing and interpreting the resulting causal configurations within and across cases. Thus, it is well fitted for an explorative research design [50, 51]. To meet standards of "good" QCApractice, we adhere to the 4-step transparency procedure of [52] comprising: (1) identifying causal factors and relevant cases, (2) calibrating the data, as well as analyses of (3) necessity and (4) sufficiency [44].

\subsection{Empirical data-base}

We rely on original, individualized, and crosssectional data from a broader, and publicly funded research project [53], where we could realize a net convenience sample of 159 senior-level company representatives from Switzerland as key informants [19]. We were interested in what smart technologybased control applications are used, how they are implemented, and how our key informants, HR managers, perceive trust as an enacted principle in their companies. We ensured a maximum dispersion of companies in terms of business sector distribution and company size since business ethics and legal scholars pointed us to company size and degree of regulation in the business sector as critical variables for practically seizing the benefits of datafication [see 54]. Hence, $22 \%$ of our sample companies stem from the finance and insurance sector, $19 \%$ from manufacturing and production of goods, $12 \%$ from public administration, national defense, and social insurance, $10 \%$ from health care, $9 \%$ from information and communication technology and $8 \%$ from trade, retail, and repair. The remaining $30 \%$ comprises companies from education, $\mathrm{NGO}$, energy, entertainment, construction, agriculture, and forestry. Since the use of datafication control only makes economic sense above a certain company size [e.g., 55], 94.7\% of our sample companies meet the European Union 250 employees-threshold of a large company, of which $70 \%$ have more than 500 employees.

Initially, we asked the respondents to assess the permeation level of their organizational control systems with datafication technology. To this end, we relied on qualitative insights of Schafheitle and colleagues [14] to present a comprehensive list of practical datafication control applications, asking them to tick all those they already use. From this, we built a summary index ranging from 1 (i.e., one tool in use) to 15 [i.e., all tools from the list in use, see also 56]. Moreover, we treat the original framework dimensions of Schafheitle and colleagues [14] as survey variables and the specifying elements as constitutive items, whenever appropriate. We followed Boselie and colleagues [57, p. 74] and measured each framework dimension by its perceived intensity (i.e., "To what extent do you believe your employees to be exposed to [...]?"). Yet, we measured the dimension "Openness for Employee Participation" in terms of its occurrence: "To what extent are employees able to voluntarily contribute additional information about themselves to HR Analytics [...]". Intensity perceptions of HR managers were measured via 5-point Likert scales, since nominal measures (i.e., yes/no) tend to fall short on measurement validity of HR instruments, such as datafication control [57]. With regards to our outcome of interest (i.e., trust inside the 
company), we included the 4-item internal trust measure, which has proven to be a valid assessment of trust "as an enacted principle" (5-point Likert scale) [18, p. 89]. From this, we inferred that if senior-level managers perceived the internal trust in their companies as high, then their company places great value on it, and vice versa [see 58].

\subsection{Causal conditions and relevant cases}

As outlined above, this csQCA builds on the empirically validated tool compromising eleven dimensions with two to six specifying elements (i.e., 36 elements) to measure and map over 230'000 possible datafication control configurations inside organizations. The dimensions comprise the basic premises of traditional control theory (e.g., control timing, targets, and scope) but also datafication control-unique dimensions, such as the datafication control's openness for employee participation or the degree to which employees understand the functioning of datafication control, amongst others. For csQCA application, we treat such dimensions as causal conditions hereafter. As csQCA is best executed with a small to an intermediate number of causal conditions, we reduced the original framework [42]; to arrive at a meaningful reduction of the original framework dimensions, we built on insights from electronic performance monitoring [e.g., 16] and human-machine interaction [e.g., 59]. We ensured maximum variability of causal conditions by focusing on the (a) "organizational layers", i.e., technologydesign and implementation strategies as well as (b) "permeation layers" of employees' working and living reality within and beyond the workplace. These two layers have been shown to matter if one wants to understand the impact of smart technologies on employees' perceptions, and hence likely on trust inside the organization $[33,60,61]$.

The organizational layer related to the design and implementation of datafication control is represented with the dimension openness for employee participation as a first causal condition. Furthermore, the implementation strategies are captured by employees' possibilities to opt-out from the use of datafication control as well as through the dimension transparency, that is employees' knowledge on what data is gathered and why it is analyzed [39]. For the "permeation layer", we included the dimension analytical capacity, because, from a trust perspective, the more "intelligent" a datafication control system gets, the greater its automation potential of HR decisions. Finally, as the last dimension, we wanted to capture the "visible employee" [62] and, hence, combined target of control (outcomes and behaviors) as well as its scope (on-the-job and offthe-job) to emphasize the pervasive nature of datafication technologies', which does not stop at the company premises' doors [62, 63]. With regards to relevant cases, we analyzed the empirical company distribution of our summary datafication permeation index, having a modal value of 0 , a median value of 2 , and, for diagnostic-descriptive means, a mean value of 2.8. However, to arrive at a meaningful interpretation of our emerging causal configurations across- and withincase, the cases should a priori exhibit a prima facie datafication permeation of their control system [47, 64]. We decided to select only companies above the $50 \%$ quartile of our datafication permeation summary index, yielding $n=73$ cases for csQCA. At a closer inspection, the final number of cases comprise tend to be large companies ( $>400$ employees) from more regulated business industries, such as finance and insurance, manufacturing and production of goods as well as public administration, social insurance, and healthcare.

\subsection{Calibrating the crisp-set data}

We calibrated our original survey data for csQCA in 1 (i.e., fully in) and 0 (i.e., fully out) in line with the recommendations of Rihoux and De Meur [20]. They strongly advise against simply performing an arithmetic median split of Likert-scale values, but to include contextual information as external standards to make the "quantification" of each case company meaningfully interpretable. In our case, we paid special attention to the Swiss legal context as well as on macro-economic peculiarities. For the Openness for Employee Participation (PART), we calibrated the degree to which employees can contribute additional information to datafication controls to make its data-gathering and analyses more accurate. The Swiss legal framework can be described as quite employer-friendly and thus leaves great leeway for interpretation, as to whether and how much to allow employees to participate. Hence, a high degree of employee participation is completely voluntary and can be seen as a strong additional effort. By employee opt-out (OPT), we understand the existence of a formal opportunity for employees to withdraw from being a target of datafication control. Under Swiss labor and obligation acts as well as under GDPR, where data processing relies on employee consent, employees may withdraw their consent at any time. In addition, the GDPR deals with the principle of purpose limitation and data minimization, i.e. only data that is required for the indicated purpose must be processed. This means that datafication may only take place within time and scope limits (i.e., to fulfill the employment contract obligations or to assess the suitability of the employee or candidate). Hence, calibration of opt-out mirrors a company's legal norm compliance. With transparency (TRAN), we 
understand the quality of knowledge, employees have concerning what data about them are gathered and why they are analyzed in the realm of datafication control. Transparency is a core feature of GDPR and legally manifests in the obligation to provide prior current, specific and understandable information to employees, on what the technology measures and analyzes. However, the norm gives a wide scope of interpretation for practical application. Hence, a high degree of transparency exceeds what is customary in a particular industry. We calibrate the automation potential (AUT) of datafication controls based on their descriptive, predictive and prescriptive technological capabilities [65]. In short, datafication control has the potential not only to provide "advice and assistance" to leaders (descriptive) but also to suggest decisions (predictive) or even execute them itself (prescriptive). Building on the "Automating Society Switzerland"[66] report, however, the maturity of "intelligent" datafication controls is rather sparsely overall, and if at all, it is used to re-analyze existing data a second time. With Visible employee (VISIB), we calibrate the degree of granularity, to which datafication controls permeate employees' personal spaces and hence, to which extent companies take the risk of unintentionally invading employees' privacy. In Switzerland, however, the integrity and self-determination of the population have a very high historical value and easily translate as an unwritten principle of "good business practice", also from a legal perspective. Finally, trust inside the organization (TRUST) is fairly pronounced in Swiss workplaces and safeguarded by particular dataficationrelevant government initiatives, data ethical investments, and nationwide role model projects. As a result, we calibrated companies' trust variation according to these high trust baseline [66].

\section{Results and interpretation}

Initially, we performed a superset- and XY-plot analysis to examine if some of our conditions are necessary for a trust-enabling use of datafication control. Technically, we analyzed if one or more of our causal factors are so-called supersets of the outcome, indicating that an enabling use of datafication control cannot occur without such condition(s) being present and/or absent. We evaluated the consistency values of our superset analysis which, if they exceed 0.95, indicate necessity [52]. As a result, none of our causal

1 Note: The survey and additional data-analysis material can be accessed via https://cutt.ly/0EhhqA3.

${ }^{2}$ Note: $\left(^{*}\right)$ represents a logical AND, $(+)$ represents a logical OR, and $(\sim)$ indicates the absence of a causal condition. The table reads from top left to bottom right and displays four jointly sufficient trustenabling configurations of datafication control We dispense with a conditions' single and joint presence or absence exceeded this threshold (PART $=0.79 ; \sim \mathrm{VISIB}=0.75$ ).

Consequently, we performed a truth table analysis for (joint) sufficiency ${ }^{1}$. We set the frequency threshold of cases to 1 and the consistency cutoff to 0.75 , similar to what Fiss and colleagues [46] have outlined as "good practice" for truth table minimization. We also checked for the robustness of our analysis as we iterated the analysis with a slightly higher and lower cutoff value; particularly, the results of the stricter cutoff value support our final determination of 0.75 . Besides, we allowed the analysis of all conditions as present or absent. Building on the most recent insights of Thiem $[67$, p. 4], we present the parsimonious solution of our truth table minimization (Table 1), since it has proven most robust in terms of causal inference and with regards to the strict treatment of logical remainders (i.e., possible configurations that lack empirical support). As a result, we can identify four causal configurations that make up an enabling use of datafication control (the a's and b's indicate the similarity of our emerging causal configurations through factoring out ${ }^{2}$ :

Table 1

Four distinct causal configurations of an enabling use of datafication control inside organizations

\begin{tabular}{lllll}
\hline OPT $^{*}$ & PART * & TRAN & $+(1 \mathrm{a})$ & \\
VISIB $^{*}$ & PART * & AUT & $+(1 b)$ & \\
AUT $^{*}$ & OPT & & $+(2 a)$ \\
AUT * & TRAN & & $(2 b)$ & $\rightarrow$ TRUST \\
\hline
\end{tabular}

\subsection{Across-case interpretation}

The first two configurations are summarized as 1a) and $1 \mathrm{~b}$ ) because they share the presence of openness for employee participation (PART) at a minimum; the same holds for the second two, relating to the (higher) automation potential of datafication control applications (AUT). In the remainder, each causal recipe is described as well as evaluated with regards to its quality parameters, namely consistency, and coverage (both ranging between 0 and 1). Briefly, consistency (which mirrors significance in variance-based analyses) relates to how well the relationship of causal conditions postulated in the configuration for a particular outcome fits with the empirical data. Hence, a high consistency value indicates that a particular configuration is a wellsuited explanatory model for the outcome of interest. Coverage resembles well with the premises of $\mathrm{R}^{2}$ and

tabular presentation of the results [45]; yet all relevant quality parameters are discussed in body text [42]. 
indicates empirical relevance, i.e. how many cases empirically share a configuration [68]. In the overall view, our four causal configurations show a consistency of 0.916 indicating a very well-fitting explanatory model of our data. Coverage displays 0.392, indicating that our overall model covers roughly 30 out of 72 companies. It is noteworthy, however, that a small-tomedium size coverage is no "knockout" criterion. In contrast, it rather urges researchers to dive into the idiosyncrasy of therein contained cases to make an overall and meaningful theoretical contribution [47].

The first causal configuration (OPT*PART*TRAN) indicates that the joint combination of openness for employee participation, the possibility to opt-out from being a target to datafication as well as transparency, i.e., employee knowledge on what data is gathered, how and why it is analyzed, is related positively to trust inside the organization. This configuration has perfect consistency $(=1)$ and shows a unique coverage of 0.04 (equaling 3 cases). The second configuration (VISIB*PART* $*$ AUT) displays that a privacy-invasive use of datafication technology can go hand in hand with trust, if it is jointly enacted with possibilities for employees to participate in the design of datafication control and if datafication technology's prescriptive capabilities are absent. Similarly, this configuration exhibits perfect consistency $(=1)$ and covers approx. $10 \%(\mathrm{n}=7)$ of the cases. The third and fourth configurations (AUT* (OPT+TRAN)) display that intelligent datafication technology with prescriptive capabilities can coexist with trust in the workplace if employees are allowed to opt-out from being a target of control or if the employer provides sound information on what employee-related data is gathered and why it is analyzed. Configuration 2 a) has a perfect consistency, configuration $2 \mathrm{~b}$ ) has a 0.8 consistency and both configurations cover approx. $15 \%(n=11)$ of the cases.

All our results indicate that an organization's efforts to enable employee centricity, that is to make sure that datafication controls are psychologically integrated via openness for participation or granting optout or transparency, is critical for a trust-enabling use of datafication control. At the most basic level, we find the three most salient building blocks of employeecentricity from trust and control literature to mutually reinforce each other (1a), also in the context of datafication [10,69]. Furthermore, our results show how employee centricity can mitigate obvious trust threats, that stem from augmented data gathering and analysis capabilities of datafication. Commonly, augmented data-gathering capabilities of datafication controls are often associated with risks of a trust-impairing panopticon [70]. Similarly, datafication controls' automation potential bears risks that managers no longer care about employee needs, which likely challenge the bases of trust, as well [34]. However, and as configuration $1 \mathrm{~b}$ ) indicates, panoptical effects can be mitigated, if employee centricity manifests in efforts to contextualize the gathered data, as demonstrated via PART and $\sim$ AUT. By granting employees with possibilities to provide further (contextual) information, organizations invite employees to contribute to the validity of datafication, especially in contexts where one's (performance) contribution is difficult to assess. This contextualization effort is further reinforced via a conscious forego of prescriptive capabilities in such a setting, indicating that leaders should remain as important intermediaries in making sense of the analyses and should not leave the field alone to datafication technology. Configurations 2a) and 2b) show that even a far-reaching automation potential, which can materialize in a way that datafication controls prescribe employees how to behave and react, do not necessarily need to reduce trust inside the organization. This seems to be alleviated by giving employees some type of (felt) control as they can either opt-out or feel that they understand what expectations they need to meet to navigate safely through their technologyimmersed workplace. By granting employees an opt-out option, organizations can demonstrate employeecentricity such that there is a "red line" of automation that must not be crossed. Similarly, organizations' efforts in explaining to employees what data is gathered and why it is analyzed can signal a "gift of maturity" and, hence, enable employees to participate in the organizational technology discourse on eye-level, for instance about the promises and limits of datafication.

\subsection{Within-case interpretation}

To make sense of our emerging configurations on the case level, we went back to our survey data and consulted publicly available company information, e.g., from media coverage. At a closer inspection on case level, configuration 1a) comprises companies that operate in highly regulated business sectors, such as finance and insurance, and whose business is under great public scrutiny and observation, i.e., where the public has a legitimate interest in data-sensitive business practices. Thus, this enabling datafication control configuration coincides with a broadly-based stakeholder dialogue on datafication purchase and implementation decisions and also involves external stakeholders, such as educational institutions and think tanks. These actors are known to address rather uncomfortable truths for companies with regards to technology deployment. Hence, one would not expect them as typical sparring partners in the industry; their involvement, however, is a token for employeecentricity. Different from this safeguards-oriented 
approach to trust sensitive use of datafication control, 1b) companies take a more ethics-sensible approach. This manifests in that collective norms of moral awareness [71] are rated significantly higher on average compared to our overall sample. Sample items read "In our company, we are aware of ethical issues related to People Management Analytics", "We recognize a moral dilemma related to People Management Analytics right away", or "People are very sensitive to ethical problems related to People Management Analytics." Besides, this heightened moral awareness is reflected in a salient position and lively interaction with the ombudsman, to whom employees can turn if they have concerns regarding datafication control.

Finally, companies from configurations 2a) and 2b) feature tech vanguardism, including a desire to experiment with automation and prescriptive analyses. This is reflected in a strong strategic technology orientation, as almost exclusively the top management team acts as a driving force in purchasing and implementation decisions. Besides, the almost exclusive involvement of (HR) consulting firms points to datafication control as a strategic fashion trend where firms want to become or catch up "state of the art". In this realm, employee-centricity, again, is oriented towards the duality of safeguard-oriented vs. ethicssensible approaches. Whereas opt-out favoring companies of 2a) also implement a variety of ombudsman-variants, the above-average shared moral awareness also makes 2b) companies engage in transparency-initiatives, not least because they may have realized the difficulty of offering a "real" opt-out option in a dependent employment relationship.

\section{Contribution and discussion}

Our results contribute to the still heated scientific debate on the duality of trust and control in a digital age as we can identify trust-enabling forms of datafication control $[10,12$, p. 538]. First, our results indicate that datafication control can promote trust inside organizations. Thus, similar to "traditional control", enabling datafication control configurations can be distinguished from coercive ones [43]. Particularly concerning $1 \mathrm{a}$ ) and $1 \mathrm{~b}$ ) configurations, our findings also show that datafication control is not necessarily the "new coercive" of the digital age, as some scholars argue [see 37]. Furthermore, our four trust-enabling datafication control configurations highlight that an organization's active stance for employee centricity in datafication control matters for a trust-enabling enactment. The identified levers of employee-centricity can ensure employee self-determination, learning, and leeway for adaption in the context of datafication control, hence make them no longer convey solely coercive, but, as a result, trust-enabling information [10]. Thus, we contribute insights on what can be done to make datafication control "a holistically appealing experience to workers" as Cardinal and colleagues [12] lament to be missing. Secondly, our study contributes to the scarcity of configurational methods in studying (datafication) control and trust relationships. Echoing Misangyi and colleagues [29], there is much theorizing about control and trust configurations, but seldom empirical testing; if at all, with moderation analyses. However, such variance-based analyses fall short of proofing the theoretical claims of non-linearity, asymmetry, and idiosyncrasy, that make the controltrust relationship an agentic, dynamic, and idiosyncratic accomplishment. Thus, our results highlight that there is no silver bullet of enabling datafication control but that variants of designing employee-centricity can be effective or ineffective in promoting trust, highly dependent on the technology design and the embedding context $[30,72]$. Practitioners might use our results as a tentative start to either assess their datafication control system's trust implications or to actively engage in a discourse on how to design such a system. For instance, practitioners might use $1 \mathrm{~b}$ ) as a guiding principle if third-party authorities require fine-grained data analyses or $2 \mathrm{a}$ ) and $2 \mathrm{~b}$ ) if opt-out is legally not feasible.

\section{Limitations}

Of course, our study is not without limitations. We outline them as avenues for further research. First, future studies should employ trust measures, that focus on specific trust relationships, i.e. differentiate trust between peers, trust between employees and leaders, and employee trust in their employer by measuring them separately (and from the trustors' perceptive). Building on the insights of Long and Sitkin [10] for traditional organizational control, we assume that these various relationships are impacted by datafication controls in many, even unforeseen ways. For instance, we can imagine that trust in the leader can get strained strongly particularly if prescriptive analytics is used [35]. Additionally, we propose that further research should use different samples from different countries to contribute to the robustness and generalizability of our results, which are, of course, limited. For instance, future studies could compare countries that differ with regards to technology governance mechanisms, legal frameworks, or the populations' general attitude towards technology. Finally, our csQCA application is an explorative, structure discovery method. Future studies can build on the growing cumulative knowledge on enabling vs. coercive archetypes of datafication control to delineate hypotheses suitable to be tested with a variety of other, more variance-based analytical 
methods. In all, our results not only contribute to the ongoing debate on how controls and trust relate in $21^{\text {st }}$ century organizations but also might guide leaders in designing datafication control systems that do not have a Taylorism coating but a human spark. Eventually, only those companies will probably come out on top who ignite the human spark as a source of value creation.

\section{References}

[1]LaBerge L, O'Toole C, Schneider J, Smaje K. How COVID-19 has pushed companies over the technology tipping point-and transformed business forever. https://mck.co/34BsxUg (May 19th, 2021).

[2]Cukier K, Mayer-Schoenberger V. The rise of Big Data. Foreign Affairs. 2013. pp. 27-40.

[3]Mosendz P, Melin A. Bosses Panic-Buy Spy Software to Keep Tabs on Remote Workers. https://bloom.bg/2R7YZdO ( May 19th, 2021).

[4]Archyde. "Workplace analytics": Novartis monitors employees in the home office. https://bit.ly/3i46NbL (May 19th, 2021).

[5]HBS. Harvard Business School Digital Initiative [Internet]. https://hbs.me/3wMHmiR (October 14th, 2020)

[6]Stam KR, Stanton JM. Events, emotions, and technology: Examining acceptance of workplace technology changes. ITP. 2010. pp. 23-53.

[7]Coovert MD, Thompson LF. The psychology of workplace technology. New York: Routledge; 2014.

[8]Gustafsson S, Gillespie N, Searle R, Hope Hailey V, Dietz G. Preserving organizational trust during disruption. Org Stud. 2020. pp. 1-25.

[9]Mishra AK, Spreitzer GM. Explaining how survivors respond to downsizing: The roles of trust, empowerment, justice, and work redesign. AMR. 1998. pp. 567-88.

[10]Long CP, Sitkin SB. Control-trust dynamics in organizations: Identifying shared perspectives and charting conceptual fault lines. AOM Annals. 2018. pp. 725-51.

[11]Leicht-Deobald U, Busch T, Schank C, Weibel A, Schafheitle S, Wildhaber I, et al. The Challenges of Algorithm-Based HR Decision-Making for Personal Integrity. J Bus Ethics. 2019. pp. 377-92.

[12]Cardinal LB, Kreutzer M, Miller C. An aspirational view of organizational control research: Re-invigorating empirical work to better meet the challenges of 21 st century organizations. AOM Annals. 2017. pp. 559-92.

[13]Nilsson NJ. Principles of artificial intelligence: Morgan Kaufmann 2014.

[14]Schafheitle S, Weibel A, Ebert I, Kasper G, Schank C, Leicht-Deobald U. No stone left unturned? Towards a framework for the impact of datafication technologies on organizational control. AMD. 2020. pp. 455-87.

[15]Wu K, Zhao Y, Zhu Q, Tan X, Zheng H. A meta-analysis of the impact of trust on technology acceptance model: Investigation of moderating influence of subject and context type. IJIM. 2011. pp. 572-81.

[16]Ravid D, Tomczak D, White J, Behrend T. EPM 20/20: A review, framework, and research agenda for electronic performance monitoring. JOM. 2020. pp. 100-26.
[17]McNall LA, Roch SG. A social exchange model of employee reactions to electronic performance monitoring. Hum Perform. 2009. pp. 204-24.

[18]Huff L, Kelley L. Levels of organizational trust in individualist versus collectivist societies: A seven-nation study. Org Sci. 2003. pp. 81-90.

[19]Kumar N, Stern LW, Anderson JC. Conducting interorganizational research using key informants. AMJ. 1993. pp. 1633-51.

[20]Rihoux B, De Meur G. Crisp-Set Qualitative Comparative Analysis (csQCA). In: Rihoux B, Ragin CC, Configurational comparative methods: Qualitative comparative analysis (QCA) and related techniques. 51: SAGE Publications; 2009. p. 33-68.

[21]Cardinal LB, Sitkin SB, Long CP. A configurational theory of control. In: Sitkin SB, Cardinal LB, BijlsmaFrankema K, Organizational Control. Cambridge, UK: Cambridge University Press; 2010. p. 51-79.

[22]Kirsch LJ, Ko D-G, Haney MH. Investigating the antecedents of team-based clan control: Adding social capital as a predictor. Org Sci. 2010. pp. 469-89.

[23] Sitkin SB, Long CP, Cardinal LB. Assessing the control literature: Looking back and looking forward. Annu Rev Organ Psychol Org Behav. 2020. pp. 339-68.

[24]Gasser U, Almeida VA. A layered model for AI governance. IEEE Internet Comput. 2017. pp. 58-62.

[25]Snell SA. Control theory in strategic human resource management: The mediating effect of administrative information. AMJ. 1992. pp. 292-327.

[26]Cascio WF, Montealegre R. How technology is changing work and organizations. Annu Rev Organ Psychol Org Behav. 2016. pp. 349-75.

[27]Lecher C. THE VERGE [Internet]. Retrieved from: https://bit.ly/3vNBGFs (July 6th, 2019).

[28]Crossover. Your Future. Streamlined. https://bit.ly/3vGMq8v (May 25th, 2021).

[29]Misangyi VF, Greckhamer T, Furnari S, Fiss PC, Crilly D, Aguilera R. Embracing causal complexity: The emergence of a neo-configurational perspective. JOM. 2017. pp. 255-82.

[30]Cardinal LB, Sitkin SB, Long CP, Miller CC. The Genesis of Control Configurations during Organizational Founding. In: Sitkin Sim B, Organization Design (Advances in Strategic Management). 40: Emerald Publishing 2018. p. 83-114.

[31]Short JC, Payne GT, Ketchen DJ. Research on Organizational Configurations: Past Accomplishments and Future Challenges. JOM. 2008. pp. 1053-79.

[32]Huselid MA. The science and practice of workforce analytics: Introduction to the HRM special issue. HRM. 2018. pp. 679-84.

[33]Spitzmüller C, Stanton JM. Examining employee compliance with organizational surveillance and monitoring. JOOP. 2006. pp. 245-72.

[34]Kellogg KC, Valentine MA, Christin A. Algorithms at work: The new contested terrain of control. AOM Annals. 2020. pp. 366-410.

[35]Schafheitle S, Weibel A, Rickert A. The Bermuda Triangle of Leadership in the AI Era? Emerging Trust Implications From "Two-Leader-Situations" in the Eyes of Employees. HICSS-54. 2021. pp. 5473-82. 
[36]Sapegina A, Weibel A. The good, the not so bad, and the ugly of competitive human resource practices: A multidisciplinary conceptual framework. Group Org Manag. 2017. pp. 707-47.

[37]Bernstein ES. Making transparency transparent: The evolution of observation in management theory. AOM Annals. 2017. pp. 217-66.

[38]Ball K. Workplace surveillance: An overview. Labor Hist. 2010. pp. 87-106.

[39]Biran O, Cotton C, editors. Explanation and justification in machine learning: A survey. IJCAI-17 Workshop on Explainable AI (XAI); 2017.

[40]Simmler M, Markwalder N. Guilty robots?-Rethinking the nature of culpability and legal personhood in an age of artificial intelligence. Crim Law Forum. 2019. pp. 1-31.

[41]Skinner D, Dietz G, Weibel A. The dark side of trust: When trust becomes a 'poisoned chalice'. Organization. 2014. pp. 206-24.

[42] Grofman B, Schneider CQ. An Introduction to Crisp Set QCA, with a Comparison to Binary Logistic Regression. PRQ. 2009. pp. 662-72.

[43]Adler PS, Borys B. Two types of bureaucracy: Enabling and coercive. ASQ. 1996. pp. 61-89.

[44]De Block D, Vis B. Addressing the challenges related to transforming qualitative into quantitative data in qualitative comparative analysis. JMMR. 2019. pp. 503-35.

[45]Aversa P, Furnari S, Haefliger S. Business model configurations and performance: A qualitative comparative analysis in Formula One racing, 2005-2013. ICC. 2015. pp. 655-76.

[46]Marx A, Cambré B, Rihoux B. Chapter 2 Crisp-Set Qualitative Comparative Analysis in Organizational Studies. In: Fiss PC, Cambré B, Marx A, Configurational Theory and Methods in Organizational Research. Research in the Soc. of Org. 38: Emerald Publishing 2013. p. 23-47.

[47]Ragin CC. Redesigning social inquiry: Fuzzy sets and beyond: University of Chicago Press; 2008.

[48]Rihoux B, Álamos-Concha P, Bol D, Marx A, Rezsöhazy I. From niche to mainstream method? A comprehensive mapping of QCA applications in journal articles from 1984 to 2011. PRQ. 2013. pp. 175-84.

[49] Woodside AG, Zhang M. Cultural diversity and marketing transactions: Are market integration, large community size, and world religions necessary for fairness in ephemeral exchanges? P\&M. 2013. pp. 263-76.

[50]Marx A. Crisp-set qualitative comparative analysis (csQCA) and model specification: Benchmarks for future csQCA applications. IJMRA. 2010. pp. 138-58.

[51]Schneider CQ, Grofman B, editors. It might look like a regression equation... but its not! An intuitive approach to the presentation of QCA and fs/QCA results. 'Comparative Politics: Empirical Applications of Methodological Innovations'; 2006; Tokyo (Japan): Sophia University

[52]Schneider CQ, Wagemann C. Standards of good practice in qualitative comparative analysis (QCA) and fuzzy-sets. Comp Sociol. 2010. pp. 397-418.

[53]Weibel A, Wildhaber I, Leicht-Deobald U, Schank C, Busch T, Kasper G, et al. Big Data or Big Brother ? - Big Data HR Control Practices and Employee Trust. SNF; 2017.
[54]Ebert I, Wildhaber I, Prassl J. Big Data in the Workplace: Privacy Due Diligence as a human rights-based approach to employee privacy protection. BD\&S. forthcoming.

[55]Hamilton R, Sodeman WA. The questions we ask: Opportunities and challenges for using big data analytics to strategically manage human capital resources. Bus Horiz. 2020. pp. 85-95.

[56]Boon C, Den Hartog DN, Lepak DP. A systematic review of human resource management systems and their measurement. JOM. 2019. pp. 2498-537.

[57]Boselie P, Dietz G, Boon C. Commonalities and contradictions in HRM and performance research. HRMJ. 2005. pp. 67-94.

[58]Nishii LH, Lepak DP, Schneider B. Employee attributions of the "why" of HR practices: Their effects on employee attitudes and behaviors, and customer satisfaction. Pers Psychol. 2008. pp. 503-45.

[59]Peters D, Calvo RA, Ryan RM. Designing for Motivation, Engagement and Wellbeing in Digital Experience. Front Psychol. 2018.

[60]Murray A, Rhymer J, Sirmon DG. Humans and technology: Form of conjoined agency in organizations. AMR. in press.

[61]Weibel A, Six F. Trust and control: The role of intrinsic motivation. In: Bachmann R, Zaheer A, Handbook of Advances in Trust: Edward Elgar Publishing 2013. p. 57-81.

[62]Stanton JM, Stam KR. The visible employee: Using workplace monitoring and surveillance to protect information assets--without compromising employee privacy or trust: Info. Today; 2006.

[63]Ball K. Electronic surveillance in the workplace. In: Smith V, Sociology of work: An encyclopedia: SAGE Publications; 2013.

[64]Yin RK. Case study research and applications: Design and methods.: Sage Publications; 2018.

[65]Lepenioti K, Bousdekis A, Apostolou D, Mentzas G. Prescriptive analytics: Literature review and research challenges. IJIM. 2020. pp. 57-70.

[66]Chiusi F, Fischer S, Kaiser-Brill N, Mätzener A, Spielkamp M. https://bit.ly/3cg1bHq (June 4th, 2021).

[67]Thiem A. Beyond the Facts: Limited Empirical Diversity and Causal Inference in Qualitative Comparative Analysis. SMR. 2019. pp. 1-14.

[68]Greckhamer T, Furnari S, Fiss PC, Aguilera RV. Studying configurations with qualitative comparative analysis: Best practices in strategy and organization research. Strateg Org. 2018. pp. 482-95.

[69]Weibel A, den Hartog DN, Gillespie N, Searle R, Six F, Skinner D. How do controls impact employee trust in the employer? HRM. 2016. pp. 437-62.

[70]Bhave DP, Teo LH, Dalal RS. Privacy at Work: A Review and a Research Agenda for a Contested Terrain. JOM. 2020. pp. 127-64.

[71]Arnaud A. Conceptualizing and measuring ethical work climate: Development and validation of the ethical climate index. Bus Soc. 2010. pp. 345-58.

[72]Fulmer CA, Gelfand MJ. At what level (and in whom) we trust trust across multiple organizational levels. JOM. 2012. pp. 1167-230. 